\title{
ADVANCES IN HOMOPOLAR WELDING OF API LINEPIPE FOR DEEPWATER APPLICATIONS
}

\author{
R.W. Carnes, R.S. Hudson, and S.P. Nichols \\ Center For Electromechanics \\ The University of Texas at Austin \\ PRC, Mail Code R7000 \\ Austin, TX 78712 \\ (512) 471-4496 Fax (512) 471-0781
}

\begin{abstract}
The University of Texas at Austin Center for Electromechanics is conducting a research program to study homopolar welding of line pipe for J-Lay applications. In 1995 , the third year of the five year research program, process improvements increased Charpy V-Notch impact toughness properties to near parent metal values, while maintaining acceptable strength. After demonstrating repeatable performance, research focused on real world effects including evaluating the effect of poor fit up resulting from misalignment and rough and wavy interfaces. During the final year of the research program, the pipe welding program has scaled up to 12 -inch nominal line pipe, a sevenfold increase in cross-sectional area. The paper will cover basics of homopolar welding, mechanical properties, weld upset profile, HPW metallurgy, and the studies of real world effects. Results from homopolar welding of 12 -inch pipe will also be presented.
\end{abstract}

\section{HOMOPOLAR OFFSHORE PIPELINE WELDING RESEARCH PROGRAM}

A consortium of six oil companies (Amoco, BP, Exxon, Mobil, Shell, and Texaco), a welding contractor (CRC-Evans), an equipment contractor (Parker Kinetic Design) and two federal agencies (the Office of Pipeline Safety of the DOT and the Mineral Management Services of the DOI) funded this joint industry program (JIP) to develop homopolar welding for J-lay applications. The research, which started in February 1993, is being conducted at UT-CEM, and has achieved the following major objectives:

- optimize weld parameters for homopolar welding 3-inch HSLA API 5L line pipe 
- investigate a range of materials with varying strength, wall thickness, composition, heat treatment and manufacturing method

- produce 3-inch welds with acceptable mechanical properties

- improve the finished weld profile

- design and build a laboratory welding fixture for joining 12-inch Schedule 80 line pipe

- demonstrate homopolar weldability of 12 -inch pipe

- transfer technology in preparation for commercialization of HPW

- develop an NDE program

\section{HOMOPOLAR WELDING}

Homopolar Welding (HPW) is a resistance forge welding process that uses the high amperage direct current discharge from a Homopolar Generator (HPG) to produce full circumferential pipe welds in under five seconds without using filler metal.

A homopolar welding system consists of a homopolar generator and a hydraulic welding fixture. The homopolar generator is an inertial energy storage device that provides the mega-ampere direct current electrical pulse to resistively heat the joint for welding. The hydraulic welding fixture delivers the current to the workpiece, provides the forging force to upset the heated interface material, and maintains alignment during upset.

\section{Homopolar Generators}

Homopolar generators are simple industrial machines that convert the stored rotational kinetic energy of its spinning rotor to direct current electric energy by electromagnetic induction. The low voltage, high current discharge, characteristic of these machines, makes them well suited for electrical resistive heating. A magnetic field imposed across the electrically conductive rotor produces a voltage and supplies a characteristic current pulse when connected to a discharge circuit. The principle of electromagnetic induction is demonstrated in the Faraday disc, or more fundamentally by moving a straight conductor though a magnetic field.[1] 


\section{The Hydraulic Welding Fixture}

This fixture consists of a hydraulic press capable of delivering the forging load and the portion of the discharge circuit that delivers the current pulse to the workpiece. The copper electrodes deliver the current for welding through the outer pipe wall and are uniformly spaced around the circumference of the pipe and clamped to its outer surface. In the laboratory fixture, short pipe sections are joined with the upset load applied through the ends. The load is controlled via a servo valve and a control system.

\section{HPW Welding Cycle}

A typical HPW cycle begins by accelerating the HPG to a preset speed, then energizing the field coils to produce a uniform magnetic field across rotor. Lowering the brushes produces a potential across them. At the discharge speed set point, a switch is closed and the stored energy of the HPG rotor converts to a direct current pulse as electromagnetic torque rapidly stops the rotor. The current is directed through the discharge circuit containing the workpiece. Due to its substantially higher resistance, the interface and adjacent material rapidly heat and soften permitting forging to form the finished weld. Homopolar welds have a narrow heat affected zone (HAZ) due to the short thermal cycle with resistance heating concentrated at and near the interface. Figure 1 shows a schematic of the homopolar welding process.

The present HPW method uses shaped pipe ends and constant, high interface pressure to control resistive heating as the current pulse discharges through the weld circuit. The shaped pipe end, a modified double bevel preparation, is prepared by machining the pipe wall from both inside diameter (ID) and outside diameter (OD) surfaces, resulting in a reduction in cross-sectional area near the interface. The reduced cross-section increases the local current density and Joule heating rate, allowing improved control of temporal and spatial temperature profiles, without relying only on thermal diffusion to heat adjacent material.

\section{3-INCH WELDING PROGRAM}


As previously reported,[2,3] four different API $5 \mathrm{~L}$ materials were under investigation in the JIP, two X52 Schedule 160, two Schedule 80, an X60 and an X65. The materials, designated A, C, B, and D, are listed in table 1. Mechanical testing consisted of tensile testing, Charpy V-Notch impact toughness testing, hardness testing and metallurgical examination. Impact tests were performed at $0^{\circ} \mathrm{C}$ on full size specimens $(10 \times 10 \times 55 \mathrm{~mm})$ in materials $A$ and $C$ and on half size specimens $(5 \times 10 \times 55 \mathrm{~mm})$ in materials $B$ and $D$.

The Hammond Acceptance Criteria ${ }^{*}$ for Charpy V-notch impact toughness values for half size specimens of $X 65$ grade at $0^{\circ} \mathrm{C}$ are a minimum individual value of $25 \mathrm{~J}$ (18.6 ft-lb) and a minimum average over three tests of $32 \mathrm{~J}(23.6 \mathrm{ft}-\mathrm{lb})$. The more rigorous X65 criteria was applied to the $X 60$ specimens since an X60 criteria was not available. For full size $X 65$ grade specimens at $0^{\circ} \mathrm{C}$, the minimum individual value is 38 $\mathrm{J}(28 \mathrm{ft}-\mathrm{lb})$ and the minimum average value is $45 \mathrm{~J}$ (33 ft-lb). For the full size $\mathrm{X} 52$ grade specimens at $0^{\circ} \mathrm{C}$, the minimum individual value is $30 \mathrm{~J}(22 \mathrm{ft}-\mathrm{lb})$ and the minimum average for three is $36 \mathrm{~J}(26.6 \mathrm{ft}-\mathrm{lb})$.

Full strength was achieved in all but the B material, which displayed a slight loss of both yield and tensile strength. Materials $A$ and $C$ failed to meet the impact toughness criteria. Further attempts to join these two materials were postponed as both were judged to have compositions unsuitable for homopolar welding. In contrast, materials $B$ and $D$ consistently achieved better than $75 \%$ of parent metal impact toughness values, far surpassing the sponsor criteria. Tensile testing was discontinued after testing demonstrated consistent yield and tensile properties in these welds. Hardness testing was continued, and Charpy V-Notch impact toughness testing became the primary criteria for judging weld quality.

Material D- 3-inch X65 Quenched and Tempered. Over 70 welds have been produced in material $D$, investigating the effect of varying six of the seven modified weld parameters. Twenty-four of these welds constituted three fully saturated, three parameter, two level test matrices, designed to investigate weld parameter primary

\footnotetext{
* The Hammond Acceptance Criteria was developed by John Hammond as an industrial standard for the new welding method compatible with existing standards.
} 
effects and interactions. The results for 70 welds, produced under ideal conditions with identical interface preparation on both pipe ends, are summarized in table 2 . The minimum CVN average is based on the single low value for each weld tested. The range of weld parameters used for these welds in presented in table 3.

From these welds, six welds failed to meet the average impact toughness requirement, and three additional welds had a single low test result, less than the minimum individual value. All that failed the average value criteria were performed with the shape factor set at an extreme values, while all that failed the individual value criteria were from welds performed with parameters that minimized displacement.

Material D Metallurgy. The base metal is a quenched and tempered, low carbon, Niobium micro-alloyed material, having a fine grained microstructure (fig. 2). The weld line microstructure displays a similar to parent metal grain size and morphology with slight coarsening through the HAZ (figs. 3 and 4).

Weld Profile. The macrograph in figure 5 shows the material flow during the forging process and the finished weld profile, which has a small weld bulge with a thin "fin" extending from its center. The extruded "fin" contains the interface and adjacent material that experienced the highest temperature (fig. 6) and much of the original interface material.

Adjustments made to the joint profile improved the shape of the weld bulge and produced the fin, which can be easily removed following the weld. After skiving the fin, the final profile will have a slight weld bulge, smoothly transitioning from the wall with no weld line crack or other stress riser.

Material D Typical Hardness and Strength. A hardness traverse for a typical material $D$ weld is presented in figure 7. All welds in material $D$ have a similar hardness profile: HAZ softening 5 to $7 \mathrm{~mm}$ on either side of the weld line and hardening at the weld line. The degree of HAZ softening and weld line hardening is primarily controlled by the discharge speed and field current parameter selection. Tensile specimens fail in the base metal at parent metal values.

Material B- 3-inch X60 ERW. Weld parameters selected for material B welds were repetitions of those used on good quality material D welds. In all such welds, the 
thermal and mechanical response was similar to those of D material welds, and the mechanical properties of the welds met the acceptance criteria with the exception of the tensile strength, as reported earlier.

Material B Metallurgy. The base metal is a controlled rolled low carbon, Niobium micro-alloyed material, having a very fine grain, and the weld line microstructure has a similar fine grained microstructure (figs. 8 and 9). Moving through the HAZ, the carbide colonies become more pronounced due to the light banding in the base metal.

Material B Typical Hardness and Strength. A hardness traverse for a typical material $B$ weld is presented in figure 10. Compared to material $D$, the HAZ has a similar width but with more softening, and lacks any weld line hardening. Tensile test specimens consistently fail at the weld line at $85-90 \%$ of parent metal strengths and display ductile fracture surfaces. These results are consistent with the thermal cycles in controlled rolled materials, and PWHT of these welds was observed to further soften the HAZ.[4]

\section{Real World Condition Welds}

Twenty-five additional material D welds were performed using the modified weld parameters to determine tolerances on joint geometry, interface alignment and surface conditions. These results are summarized in table 2 . In the misalignment series, pipes with standard end preparations were misaligned by displacing the pipe centerlines radially and by tilting one of the pipes. The expected response to radial misalignment is circumferentially non-uniform heating from the variation in contact width and contact pressure around the interface surface. For angular misalignment, the expected response is increased contact pressure at the initial contact point. As previously mentioned, increasing the local contact pressure reduces the contact resistance and allows more current flow along that path.

In the surface condition weld studies, the interface surfaces of typical joints were single point lathe turned to produce substantially coarser finishes, cut with a full width shearing cutter, or machined to produce a wavy surface. Coarsest surface finishes 
exceeded $17.8 \mu \mathrm{m}$ rms (700 $\mu \mathrm{in}$.), and the wavy surface had a total wave amplitude of $127 \mu \mathrm{m}$ (0.005 in.).

On the last four real world welds, the joint machining was performed using a commercial pipe-facing machine leaving a coarse, wavy finish on the interface surfaces. Typically, the joints are lathe-turned producing a smooth (<1.62 $\mu \mathrm{m}$ [64 $\mu$ in]), flat surface. These welds displayed typical thermal and mechanical response and had exceptional impact toughness.

Despite parameter selection designed to produce unacceptable welds, overall, these welds achieved circumferentially uniform heating, and displayed typical displacement response. The effect of these weld parameters generally lowered the impact toughness, but only two failed to achieve the minimum average impact toughness. Three additional welds had an individual value below the acceptance limit.

\section{Discussion and Summary of 3-inch welds}

In the 3-inch homopolar welding program, four materials were successfully joined achieving full strength or near full strength joints. While all met hardness requirements, the limit on achieving acceptance for offshore pipelines remained acceptable impact toughness. The modified weld parameters achieved acceptable results in the two high strength materials, but not the lower strength materials. The weldability of materials $B$ and D was attributed to their clean chemistry and possibly the use of calcium as a manganese cleaner. Extensive studies to determine bounds of the process revealed that for a given material, acceptable welds were achievable over a broad range of parameters, permitting optimization of a single parameter.

\section{Conclusions}

The results of the 3-inch welding program permit these conclusions:

- Material chemistry strongly influences the homopolar weldability of a material.

- High strength materials are easily joined.

- Modified weld parameters produce acceptable finished profile .

- Modified parameters make HPW more robust and more tolerant to real world conditions. 
- Careful selection of weld parameters assures good welds in weldable materials.

\section{2-INCH HOMOPOLAR WELDING PROGRAM}

Success in homopolar welding of 3-inch schedule 60 line pipe led the way in the design of a fixture for joining 12-inch schedule 80 line pipe. The modified weld parameters demonstrated the robustness and simplicity of the process, while reducing some of the fixture requirements. The next section reviews the critical issues associated with scaling the process to a larger pipe, a larger cross-section, and prototype issues for a commercial fixture.

\section{Design Requirements for Scaling Up}

Historically, the homopolar welding thermo-mechanical cycle has been assumed to be independent of cross-sectional area joined. The process was treated as an adiabatic process, since the thermal cycle was so fast, and the peak current was reached in less than $4 \%$ of the pulse length. To achieve comparable thermal and mechanical responses in the larger workpiece, the local heating rates and stress distribution were maintained, and the joint profile was scaled using the wall thickness as the characteristic dimension.

To meet the thermal requirements, local current densities were maintained since the square of current density determines electrical resistance heating rates. The total current profiles for any size pipe should have the same shape, including time to peak current $(100 \mathrm{~ms})$ and the pulse length $(2.5 \mathrm{~s})$ and they should scale with the crosssectional area.

To maintain the stress distribution, upset load requirements should scale with pipe wall area as well. Further, during upset, when the workpiece deforms, the rate of deformation was to be maintained.

Some of the general requirements for successful homopolar pipe welding:

- circumferentially uniform current distribution 
- minimal circuit losses

- maintain axial alignment during upset

- limit electrode leading edge peak current density.

\section{Prototype 12-inch HPW Machine}

The first prototype HPW machine for joining 12-inch line pipe was implemented as a laboratory fixture primarily to demonstrate the scalability of HPW. Of interest was whether the required current pulse could be introduced into a pipe and whether the pipe would heat and forge similar to the 3-inch welds.

The new welding machine consisted of a two piece welding fixture and three 10 MJ HPGs. The hydraulic load module of the welding fixture provides an upset load of $1.91 \mathrm{MN}(430,000 \mathrm{lb})$ and an accumulator passively maintains a relatively constant force to the workpiece during deformation. An internal $101.6 \mathrm{~mm}$ (4 in.) diameter tension rod transmits the force from a pair of hydraulic cylinders configured in parallel and applies the upset load to the ends of the pair $152 \mathrm{~mm}$ (6 in.) long pipes.

The other component, an upset frame, contains the electrodes and busswork to transfer the current through the workpiece and maintain the axial alignment during upset. Twelve pairs of hydraulic cylinders extend and retract the electrodes and limit transverse motion of the workpiece. The three $10 \mathrm{MJ}$ HPGs are connected in parallel and capable of storing $30 \mathrm{MJ}$ of rotational kinetic energy for welding. The system is designed for a peak current of 1.5 MA.

\section{The First 12-inch Welding Series}

The material selected for this first series, designated with the prefix "N", was substantially identical to material $D$, as both were provided by the same supplier. This material has a wall thickness of $0.50 \mathrm{in}$. and wall area of $12,419 \mathrm{~mm}^{2}\left(19.25 \mathrm{in}^{2}\right)$. Material composition is listed in table 1.

As of this writing, six 12-inch welds have been completed, with all but the first two welds having sufficient energy to join the full wall and produce a finished weld profile similar to 3 -inch welds (fig. 11). The process parameters, total current, interface voltage and displacement are similar to those at the 3-inch welds. The peak current (1.43 MA), 
time to peak $(0.094 \mathrm{~ms})$ and pulse length $(3 \mathrm{~s})$ are similar to the 3 -inch, indicating that comparable energy was delivered to the workpiece. The displacement and interface voltage responses display the same response as for 3-inch welds, with the exception of the more rapid initial displacement rate. The average energy density between the interface voltage probes was also comparable to material $\mathrm{D}$ welds.

Mechanical Properties. The mechanical properties and metallurgy of the initial material $\mathrm{N}$ welds were similar to material $\mathrm{D}$ welds, with the exception of the impact toughness. The parent metal is fine-grained similar to that of material D (fig. 12). Weld metal is slightly coarser, but still fine grained and the HAZ metal is coarser still (figs. 13 and 14). The hardness traverse shows similar weld line hardening surrounded by a narrow zone of HAZ softening (fig. 15). In the tensile test, the specimens broke in the base metal at parent material properties. These welds had unacceptably low impact toughness, displaying only limited shear fracture.

Discussion of First 12-inch welds. The first 12-inch weld series successfully demonstrated the scalability of HPW to larger pipe sizes and comparability of the process parameters used to monitor the process. The failure to achieve acceptable impact toughness by the sixth weld is not unexpected. In previous welding programs, it has typically taken dozens of welds to identify weld parameters capable of increasing impact toughness, often never achieving acceptable toughness. For the first few welds, possible causes of low toughness may be related to the faster displacement rate or the slower cooling rate, both characteristics of the new welding fixture. The features of the fixture producing these effects were not in the primary design considerations. Presently, modification to the weld parameters are under consideration to adapt them to the new fixture.

\section{FUTURE WORK}

Work for the remainder of the present JIP includes continuing welding both three and twelve inch pipe and characterizing HPW flaws. The emphasis of the 12-inch welding program will be identifying weld parameters that increase impact toughness properties. The 3 -inch welding program will continue to investigate fundamental 
relationships between weld parameters as they affect the process parameters and mechanical properties.

After this JIP, a follow-on program is proposed to accomplish the following:

- Optimize weld parameters for large diameter pipe

- Complete HPW flaw characterization and develop prototype and commercial nondestructive test procedures

- Investigate homopolar weldability of other important material, like duplex, Cr-A, and titanium.

\section{COMMERCIALIZATION EFFORTS}

A joint effort by the industrial contractors of this JIP is placing a prototype HPW system in a land based operation as a low risk, first commercial operation. Parker Kinetic Designs has designed an industrial homopolar generator for joining 4, 6, and 8 in. diameter schedule 80 line pipe, with maximum pipe wall area of $8,387 \mathrm{~mm}^{2}$ (13 in. ${ }^{2}$ ). This machine produces $15 \mathrm{MJ}$ at 3,440 rpm, uses rolling element bearings, requires an eight hour brush maintenance after 10,000 discharges, and is skid mountable. Its dimensions are $1.40 \mathrm{~m}$ (55 in.) long and $1.52 \mathrm{~m}$ (60 in.) diameter, and weighs $133 \mathrm{kN}(30,000 \mathrm{lb})$.

Adapting the features of the laboratory fixture for field welding requires developing a method for gripping the pipe to apply the upset force. Field fixture design and testing is underway at CRC-Evans. Knowledge acquired from the 12-inch fixture at CEM will be incorporated in the design of the next HPW fixture.

\section{ACKNOWLEDGMENTS}

We gratefully acknowledge the support of the Joint Industry Program Sponsors, Amoco, BP, Exxon, Mobil, Shell, Texaco, CRC-EVans, PKD, and the MMS/DOT. The preliminary work necessary to initiate this program was supported by NSF through the Offshore Technology and Research Center. 


\section{REFERENCES}

[1] Halliday, D., and Resnick, R.: Fundamentals of Physics. 3rd ed. New York, John Wiley \& Sons (1988) 745.

[2] Haase, P.W., R.W. Carnes, and R.S. Hudson: "Homopolar pulse welding for offshore deep water pipelines," OTC 7814. Proceedings 27th Annual Offshore Technology Conference, Houston, TX, May 1-4, 1995.

[3] Carnes, R. and Haase, P.: "The Current State of Homopolar Pipeline Welding," proceedings, SPE 69th Annual Technical Conference and Exhibition, New Orleans, LA, Sept. 25-28, 1995.

[4] Kozasi,: "Thermomechanically Processes Steels with Improved Weldability In Welding Metallurgy of Structural Steels," Warrendale, Penn.: The Metallurgical Society, (1987) 63-77. 
Table 1. Material data

\begin{tabular}{|c|c|c|c|c|c|}
\hline Weld Prefix Code & $A$ & $\mathrm{C}$ & $B$ & $D$ & $N$ \\
\hline API 5I Grade & $\mathrm{X52}$ & $\times 52$ & $\mathrm{X60}$ & $\times 65$ & $\mathrm{X65}$ \\
\hline Outside Diameter & 3.5 & 3.5 & 3.5 & 3.5 & 12.75 \\
\hline Wall Thickness & 0.438 & 0.438 & 0.300 & 0.315 & 0.50 \\
\hline Type & seamless & ERW & ERW & seamless & seamless \\
\hline $\begin{array}{l}\text { Heat Treatment } \\
\text { (Not On Mill Test } \\
\text { Report) }\end{array}$ & Hot rolled & normalized & $\begin{array}{l}\text { controlled } \\
\text { rolled }\end{array}$ & $\begin{array}{l}\text { quenched and } \\
\text { tempered }\end{array}$ & $\begin{array}{l}\text { quenched and } \\
\text { tempered }\end{array}$ \\
\hline \multicolumn{6}{|l|}{ Ladle Chemistry } \\
\hline C & 0.23 & 0.11 & 0.13 & 0.08 & 0.08 \\
\hline $\mathrm{Mn}$ & 1.04 & 1.13 & 0.65 & 1.29 & 1.29 \\
\hline$P$ & 0.010 & 0.014 & 0.005 & 0.011 & 0.011 \\
\hline $\mathrm{S}$ & 0.009 & 0.005 & 0.004 & 0.002 & 0.0017 \\
\hline $\mathrm{Si}$ & & 0.28 & 0.22 & 0.19 & 0.19 \\
\hline $\mathrm{Al}$ & & 0.037 & 0.042 & & \\
\hline $\mathrm{Cr}$ & & 0.073 & 0.03 & & \\
\hline Mo & & 0.028 & 0.01 & 0.22 & 0.215 \\
\hline $\mathrm{Ni}$ & & 0.07 & 0.01 & & \\
\hline $\mathrm{Cu}$ & & 0.13 & 0.02 & & \\
\hline $\mathrm{Cb}$ & & 0.034 & 0.18 & 0.032 & 0.032 \\
\hline $\mathrm{Ca}$ & & & 0.0048 & 0.0026 & 0.0026 \\
\hline $\mathrm{Ti}$ & & 0.008 & & & \\
\hline $\mathrm{V}$ & 0.08 & 0.040 & & & \\
\hline $\mathrm{B}$ & & 0.0003 & & & \\
\hline Ti-Al & & & & 0.035 & 0.035 \\
\hline $\operatorname{liw} \mathrm{C}_{\mathrm{eq}}$ & 0.42 & 0.34 & 0.23 & 0.34 & 0.34 \\
\hline Yield Strength (Ksi) & 66.0 & 59.5 & 79.5 & 71.6 & 71.6 \\
\hline \begin{tabular}{ll|}
$\begin{array}{l}\text { Tensile } \\
\text { (Ksi) }\end{array}$ & Strength \\
\end{tabular} & 94.4 & 79.5 & 86.1 & 80.7 & 80.7 \\
\hline \% Elong In 2" & 30 & 37 & 22 & 26.6 & 26.6 \\
\hline $\begin{array}{l}\text { Impact Toughness } \\
\text { (J [ft-lbs]) }\end{array}$ & $\begin{array}{l}85(63) \\
\text { full size }\end{array}$ & $\begin{array}{l}\text { 214(158) } \\
\text { full size }\end{array}$ & $\begin{array}{c}81(60) \\
\text { half size }\end{array}$ & $\begin{array}{l}\text { 168(124) } \\
\text { half size }\end{array}$ & $\begin{array}{c}<358 \\
\text { full size }\end{array}$ \\
\hline Vickers Hardness & 193 & 171 & 182 & 185 & 219 \\
\hline
\end{tabular}


Table 2. Summary of mechanical test results for material $D$ welds

\begin{tabular}{|l|l|c|c|}
\hline & Units & Ideal Conditions & Real World Conditions \\
\hline \# Welds Performed & & 70 & 25 \\
\hline \# Weld CVN Tests & & 63 & 21 \\
\hline CVN Ave. & $\mathrm{J}$ & 109.1 & 101 \\
\hline CVN Ave. St.Dev & $\mathrm{J}$ & 37.7 & 34.6 \\
\hline \# Fail Ave. Criteria & & 6 & 2 \\
\hline Min CVN Ave. & $\mathrm{J}$ & 85.6 & 75.9 \\
\hline CVN Min St.DEV & $\mathrm{J}$ & 39.9 & 44.5 \\
\hline \# Fail Min Criteria & & 3 & 3 \\
\hline \# Weld Tensile Tests & & 29 & \\
\hline Yield Ave & MPa & 500 & \\
\hline Yield St.Dev & MPa & 9.5 & \\
\hline Tensile Ave & MPa & 567 & \\
\hline Tensile St.Dev & MPa & 9.5 & \\
\hline \% EL Ave & & 26 & \\
\hline \% EL St.Dev & & 1.85 & \\
\hline
\end{tabular}

Table 3. Range of weld parameters for ideal condition welds

\begin{tabular}{|l|l|c|c|c|}
\hline & Unit & Minimum Value & Maximum Value & \% Variation \\
\hline Discharge Speed & $\mathrm{rpm}$ & 2000 & 2200 & 10 \\
\hline Field Current & $\mathrm{A}$ & 300 & 390 & 30 \\
\hline Load & $\mathrm{kN}$ & 200 & 267 & 25 \\
& & & & \\
\hline Joint Angle & Deg & 30 & 45 & 33 \\
\hline Contact Width & $\mathrm{mm}$ & 1.905 & 3.81 & 50 \\
\hline Shape Factor & & 0 & 1 & 100 \\
\hline
\end{tabular}

